\section{Extending the Storage Life of 'Fuyu' Persimmon by Modified-atmosphere Packaging}

\author{
Ruth Ben-Arie and Yohanan Zutkhi \\ Department of Fruit and Vegetable Storage, Agricultural Research \\ Organization, The Volcani Center, Bet Dagan 50250, Israel
}

Additional index words. Diospyros kaki

Abstract. The commercial storage life of the nonastringent Japanese 'Fuyu' persimmon (Diospyros kaki L.), grown in Israel, was extended from 6 to 18 weeks at $0 \mathrm{C}$ by modified-atmosphere packaging (MAP) in a low-density polyethylene (LDPE) film. MAP retarded fruit softening and inhibited development of peel and flesh disorders, which limited the storage life of the naked fruit. The fruit maintained its external and internal quality within the MAP during a subsequent week at $20 \mathrm{C}$ in the $0.08-\mathrm{mm}$ LDPE film. Fruit quality deteriorated more rapidly in a $0.06-\mathrm{mm}$ package. The difference between fruit quality in the two packs is attributed to specific physiological effects of the different atmospheric equilibria established due to film thickness.

The rationale for the application of modified-atmosphere packaging (MAP) to extend the postharvest life of fresh produce is that by reducing $\mathrm{O}_{2}$ and increasing $\mathrm{CO}_{2}$ levels, respiration is inhibited and senescence is subsequently postponed (Kader et al., 1989). However, although this is undoubtedly a major effect of MAP, there are additional direct or indirect effects attributable to altered environments. These effects are not predictable and make it difficult to model the optimal commodity package on the basis of known respiratory behavior. MAP for extended storage of the nonastringent Japanese 'Fuyu' persimmon might be considered an example.

Kawada (1982) showed that 'Fuyu' fruit grown in Japan could be stored for 5 to 6 months at $0 \mathrm{C}$ if individually packed and sealed in $0.06-\mathrm{mm}$ polyethylene bags. The limiting factor was fruit softening. The same cultivar, grown in New Zealand, could be stored satisfactorily for only 4 weeks under the same conditions (MacRae, 1987). The limiting factor in this case was chilling injury, expressed as gel formation and loss of juiciness, not necessarily accompanied by fruit softening. The disorder was alleviated by MAP. Fruit of the same cultivar recently introduced from Japan and now grown in Israel has shown limited storage life in air at $0 \mathrm{C}$, due primarily to peel browning, which was not regarded as a symptom of chilling injury (MacRae, 1987), and to internal flesh browning. The purpose of this study was to examine the effect of MAP on peel and flesh browning of stored 'Fuyu' persimmons, con-

Received for publication 13 May 1991. Accepted for publication 2 Jan. 1992. This research was supported by Saphir Fruit, a division of Hunter Produce, London. The cost of publishing this paper was defrayed in part by the payment of page charges. Under postal regulations, this paper therefore must be hereby marked advertisement solely to indicate this fact. sidering that these disorders might be the result of oxidation.

'Fuyu' persimmon fruits of uniform size (60 to $65 \mathrm{~mm}$ in diameter) were harvested at full orange color (grade 5 on the Japanese color chart) (Yamazaki et al., 1981), with firmness $=110.8 \pm 9.7 \mathrm{~N}$ and soluble solids concentration $=20 \%$. The fruits were packed in groups of six in $25 \times 30$-cm lowdensity polyethylene (LDPE) bags 0.06 or $0.08 \mathrm{~mm}$ thick and sealed. Half of the bags were flushed with $\mathrm{N}$ to replace the air before sealing and half were not flushed. The packed and naked (control) fruit were stored at $0 \mathrm{C}$ for $6,10,14$, or 18 weeks. At the termination of each storage period, 12 bags per treatment and 72 unpacked fruits were transferred to 20C: one-third was examined on the same day, one-third after 3 days, and the remainder after 7 days. Before the bags were opened to examine the fruit, $30 \mathrm{ml}$ of the air within each bag was sampled with gas-tight syringes to determine the levels of $\mathrm{CO}_{2}, \mathrm{O}_{2}$, $\mathrm{N}_{2}$, and ethanol (Pesis et al., 1986). Fruit examination consisted of external and internal visual description, penetrometer determination of fruit firmness with a mounted
Hunter-Spring pressure tester using the 11mm-diameter plunger to a depth of $7.5 \mathrm{~mm}$, and flavor evaluation by a panel of 12 to 15 untrained persons.

The factors that most affected the composition of the atmosphere within the bags were the thickness of the LDPE film and the storage temperature. There were no appreciable differences between the states of equilibrium established in bags sealed initially under air or N. Average values were calculated for eight replicate flushed or nonflushed bags stored after packaging. There was little change in the respective $\mathrm{O}_{2}$ and $\mathrm{CO}_{2}$ levels throughout the storage period once equilibrium levels had been obtained in bags of both thicknesses at either temperature (Fig. 1). At $0 \mathrm{C}$ the average $\mathrm{O}_{2}$ levels at equilibrium were $13.8 \%$ and $5.8 \%$ in bags of 0.06 and $0.08 \mathrm{~mm}$ thickness, respectively. These
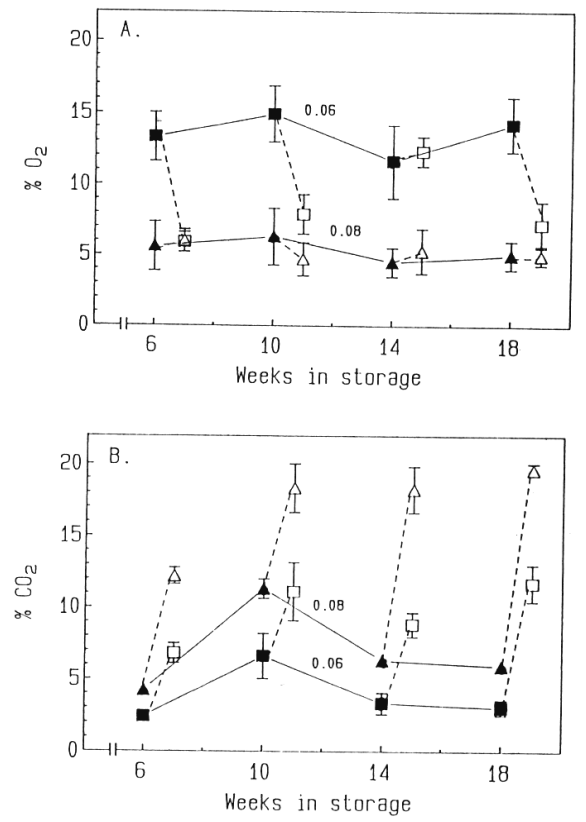

Fig. 1. Equilibrium levels of $\mathrm{O}_{2}(\mathrm{~A})$ and $\mathrm{CO}_{2}$ (B) established within low-density polyethylene bags, 0.06 or $0.08 \mathrm{~mm}$ thick, six 'Fuyu' persimmons per bag, during storage at $0 \mathrm{C}(\stackrel{\mathrm{C}}{\longrightarrow}$ and after transfer to $20 \mathrm{C}(--)$. Bars represent \pm SD.

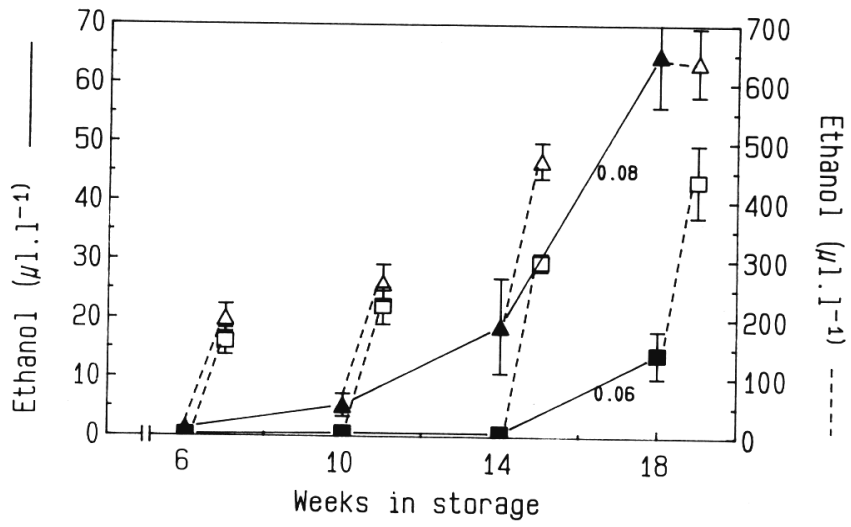

Fig. 2. Accumulation of ethanol in low-density polyethylene bags, 0.06 or $0.08 \mathrm{~mm}$ thick, six 'Fuyu'

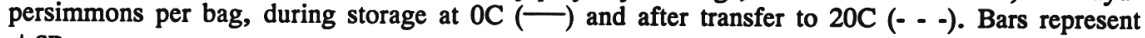
$\pm \mathrm{SD}$. 


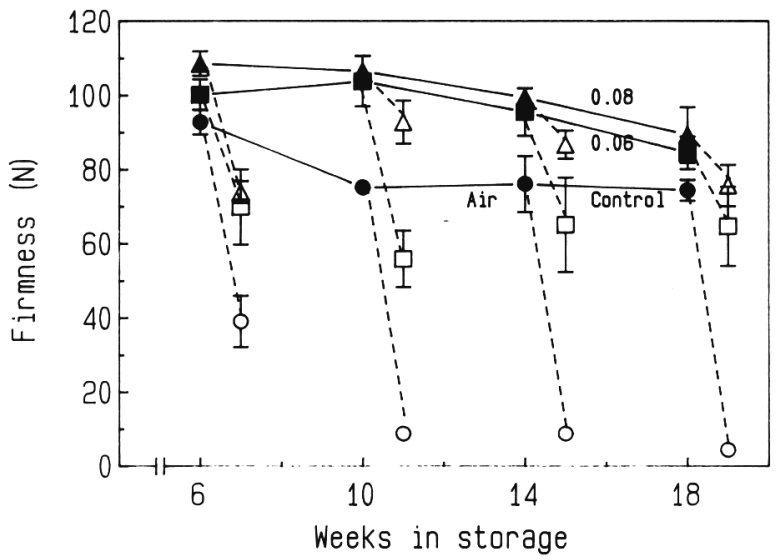

Fig 3. Firmness of 'Fuyu' persimmons stored naked in air or in 0.06- or 0.08-mm-thick, low-density polyethylene bags upon removal from $0 \mathrm{C}(-)$ and after transfer to $20 \mathrm{C}(--)$. Bars represent \pm SD.
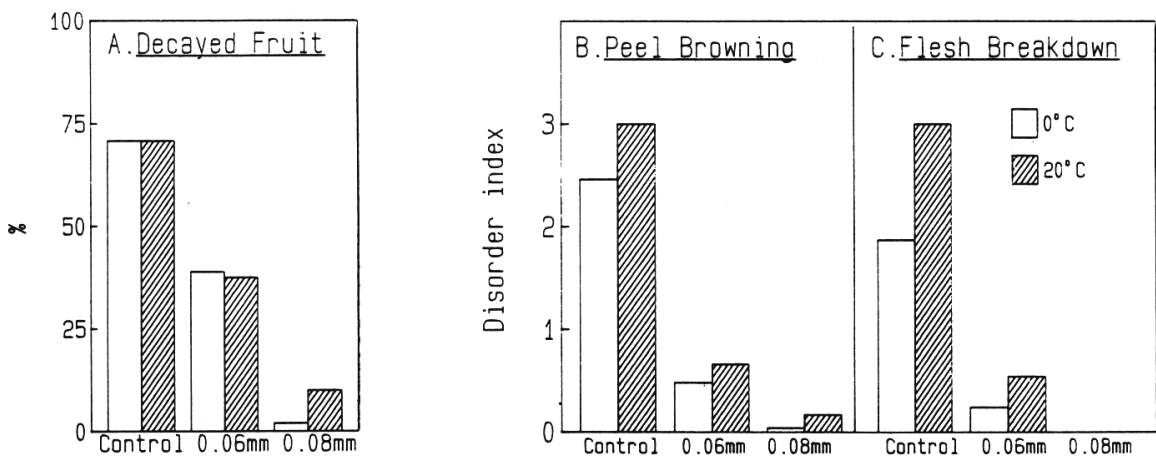

Fig. 4. Effect of MAP in $0.06-$ or 0.08 -mm-thick, low-density polyethylene bags on the extent of peel and flesh disorders in 'Fuyu' persimmons after 18 weeks of storage at $0 \mathrm{C}$ followed by 1 week at $20 \mathrm{C}$.

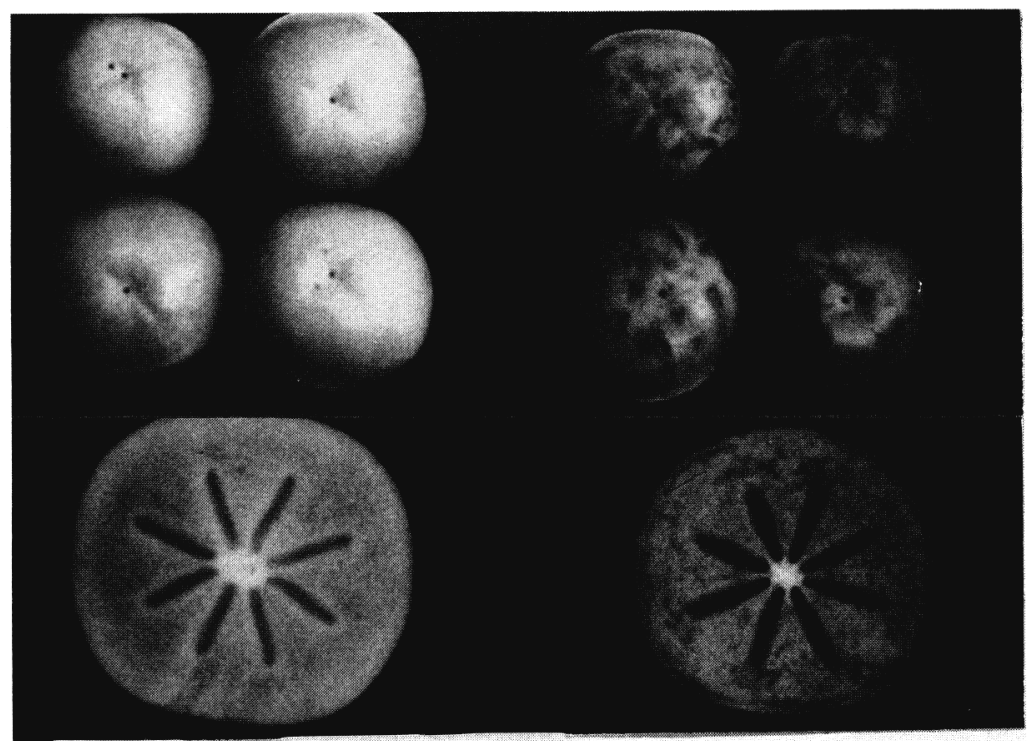

LDPE $0.08 \mathrm{~mm}$

CONTROL

Fig. 5. Effect of MAP in 0.08-mm-thick low-density polyethylene bags on peel and flesh disorders of 'Fuyu' persimmons after 18 weeks of storage at $0 \mathrm{C}$ and 1 week at $20 \mathrm{C}$.

equilibrium levels changed to $9.5 \%$ and $5.2 \%$ upon transfer to 20C. Parallel values for $\mathrm{CO}_{2}$ averaged $3.8 \%$ and $7.0 \%$ at $0 \mathrm{C}$ and $9.5 \%$ and $16.4 \%$ at $20 \mathrm{C}$, respectively.

These levels represent the equilibria established between the rates of respiration of the fruits at each temperature and the permeability rates of the LDPE films to each gas. As the respiration rate of the fruit was affected more by temperature than by the permeability of the film to either gas, transfer from 0 to $20 \mathrm{C}$ resulted in a dramatic change in equilibrium levels (Pig. 1). This change was expressed as a significant increase in $\mathrm{CO}_{2}$ concentration, which was not necessarily accompanied by a decline in $\mathrm{O}_{2}$ concentration. In the 0.06-mm LDPE bags, the $\mathrm{O}_{2}$ level did decline parallel with the rise in $\mathrm{CO}_{2}$, but in the $0.08-\mathrm{mm}$ bags, there was no further decline in $\mathrm{O}_{2}$ level at 20C. This result may indicate that the steepness of the $\mathrm{O}_{2}$ gradient between the internal and external atmospheres affected the flux of $\mathrm{O}_{2}$ into the bags so that a steady level of $\approx 5 \% \mathrm{O}_{2}$ was maintained.

The impermeability of the LDPE films to ethanol resulted in continuous accumulation of the latter in bags of both thicknesses (Fig. 2 ). The significantly greater accumulation in the $0.08-\mathrm{mm}$ bags was probably due to the lower $\mathrm{O}_{2}$ levels, which enhanced anaerobic respiration, especially at $20 \mathrm{C}$.

The modified atmospheres produced in the bags improved the keeping quality of the fruit in storage and during subsequent shelf life by retarding the rate of softening (Fig. 3) and the extent of peel disorders and flesh breakdown (Figs. 4 and 5), compared with airstored fruit. In MAP at $0 \mathrm{C}$, the fruit hardly softened in bags of both thicknesses, but upon transfer to $20 \mathrm{C}$, the rate of softening was greater in the $0.06-\mathrm{mm}$ than in the $0.08-\mathrm{mm}$ bags (Fig. 3). The correlations between fruit firmness and the levels of $\mathrm{O}_{2}$ and $\mathrm{CO}_{2}$ were similar $\left(\mathrm{O}_{2}, R^{2}=0.143, P<0.001 ; \mathrm{CO}_{2}\right.$, $\left.R^{2}=0.194, P<0.001\right)$, and the effect of MAP could not be attributed to either of them specifically. The unpacked control fruit maintained a modicum of firmness during shelf life at 20C after prior storage for only 6 weeks at $0 \mathrm{C}$ and thereafter became completely soft.

Upon removal from storage after 4 weeks, the peel of air-stored fruit began to show brown staining, and the fruit decayed during holding at $20 \mathrm{C}$ due to the development of Alternaria alternata. However, MA-packed fruit showed much less decay and peel browning, especially in the 0.08 -mm bags, even after 18 weeks of storage (Figs. $4 \mathrm{~A}$ and $\mathrm{B}, 5)$. The correlation between the degree of peel disorders and the composition of the atmosphere in the bags was highly significant: for $\mathrm{O}_{2} R^{2}=0.41, P<0.0001$; for $\mathrm{CO}_{2} R^{2}=0.25, P<0.0001$; and for ethanol $R^{2}=0.185, P<0.001$.

Internal discoloration and breakdown of the fruit flesh became apparent in the naked control fruit after 6 weeks of storage at $0 \mathrm{C}$, when the fruit was still firm. After 10 weeks of storage, flesh breakdown also occurred during the week at 20C. MA storage in 0.06$\mathrm{mm}$ bags delayed the onset of internal flesh disorders. In 0.08 -mm bags, these disorders were absent during 18 weeks at $0 \mathrm{C}$ plus 1 week at 20C (Figs. 4C and 5).

In spite of the relatively high levels of ethanol produced inside the MA bags after 7 days at 20C, following various periods of storage at $0 \mathrm{C}$, no off-flavors were detected by the taste panels at any time during the course of the trial. At those times when the control fruit was still edible, the taste panel showed no preference for these fruits com- 
pared with the MA-packed fruits or vice versa. In conclusion, MAP of the nonastringent 'Fuyu' persimmon extended the storage life of the fruit at $0 \mathrm{C}$ and added subsequent shelf life at $20 \mathrm{C}$ by delaying the rate of softening and inhibiting the onset of storage disorders. The delayed softening was probably the outcome of retarded senescence due to the inhibition of respiration at low $\mathrm{O}_{2}$ and elevated $\mathrm{CO}_{2}$ levels. The ameliorative effect on physiological peel and flesh disorders could be attributed to the direct effects of the altered atmospheric composition: 1) reduced $\mathrm{O}_{2}$ levels may have inhibited phenol oxidation that leads to the formation of brown pigments (Ben-Arie and Or, 1986) and 2) elevated $\mathrm{CO}_{2}$ levels likely were responsible for retarding decay development due to Alternaria alternata (Wells and Uota, 1970). We do not know whether the levels of ethanol produced in the MAP have any direct effect on the disorders observed.

\section{Literature Cited}

Ben-Arie, R. and E. Or. 1986. The development and control of husk scald on 'Wonderful' pomegranate fruit during storage. J. Amer. Soc. Hort. Sci. 11:395-399.

Kader, A.A., D. Zagory, and E.L. Kerbel. 1989. Modified atmosphere packaging of fruits and vegetables. CRC Crit. Rev. Food Sci. Nutr. 28:1-30.

Kawada, K. 1982. Use of polymeric films to extend postharvest life and improve marketability of fruits and vegetables-Unipack: Individually wrapped storage of tomatoes, oriental persimmons and grapefruit, p. 87-99. In: D.G. Richardson and M. Meheriuk (eds.). Controlled atmospheres for storage and transport of perishable agricultural commodities. Sym. 1, Corvallis, Ore. Timber Press, Beaverton, Ore.

MacRae, E.A. 1987. Development of chilling injury in New Zealand grown 'Fuyu' persimmon during storage. New Zealand J. Expt. Agr. 15:333-344.

Pesis, E., A. Levi, and R. Ben-Arie. 1986. Deastringency of persimmon fruits by creating a modified atmosphere in polyethylene bags. J. Food Sci. 51:1014-1016, 1041.

Wells, J.H. and M. Uota. 1970. Germination and growth of five fungi in low oxygen and high carbon-dioxide atmospheres. Phytopathology 60:50-53.

Yamazakl, T., K. Suzuki, S. Murase, and S. Otake. 1981. Color charts: Useful guide to evaluate the fruit maturation. II. Calorimetric specification of color chart for kaki fruit, cv. 'Hiratanenashi'. Bul. Fruit Tree Res. Sta. Ser. A. 8:79-84. 